Dermatology 2019;235:240-242

DOI: $10.1159 / 000496986$

\section{Insights into Worldwide Interest in Tattoos Using Google Trends}

\section{Nicolas Kluger}

Departments of Dermatology, Allergology and Venereology, Helsinki University Central Hospital, Helsinki, Finland; "Tattoo" Consultation, Department of Dermatology, Bichat-Claude Bernard Hospital, Assistance Publique - Hôpitaux de Paris, Paris, France

\section{Keywords}

Epidemiology · Internet · Google Trends · Infodemiology · Population · Search analysis · Tattoo

The prevalence of tattooing is about $10-29 \%$ worldwide $[1,2]$. However, data on the prevalence and incidence of tattooing outside Western countries (Europe, North America, and Australia) are sparse. Google Trends is a useful website that provides data on the relative search volume of queries and topics over time and across geographical areas (worldwide, country, city). It allows seasonal and long-term assessment of trends in public interest. It is currently used in health care research [3].

\section{Methods}

We analyzed the data generated through Google Trends for the relative search volumes on the topic "tattoo", worldwide from January 1, 2004 to December 31, 2018. Results are displayed as a set of time series. The values are not the actual search counts but percentages relative to the total searches across the specified geography and time period. The resulting numbers are then scaled from 0 to 100 based on the proportion to all searches on all topics. All data used in this study are publicly available, anonymous, and cannot be traced back to identifiable individuals.

\section{Results}

Between 2004 and 2018, the interest in tattoos has steadily increased (Fig. 1). The comparison of the mean search volumes by periods of 5 years illustrates the regular increase: $46 \pm 5$ (2004-

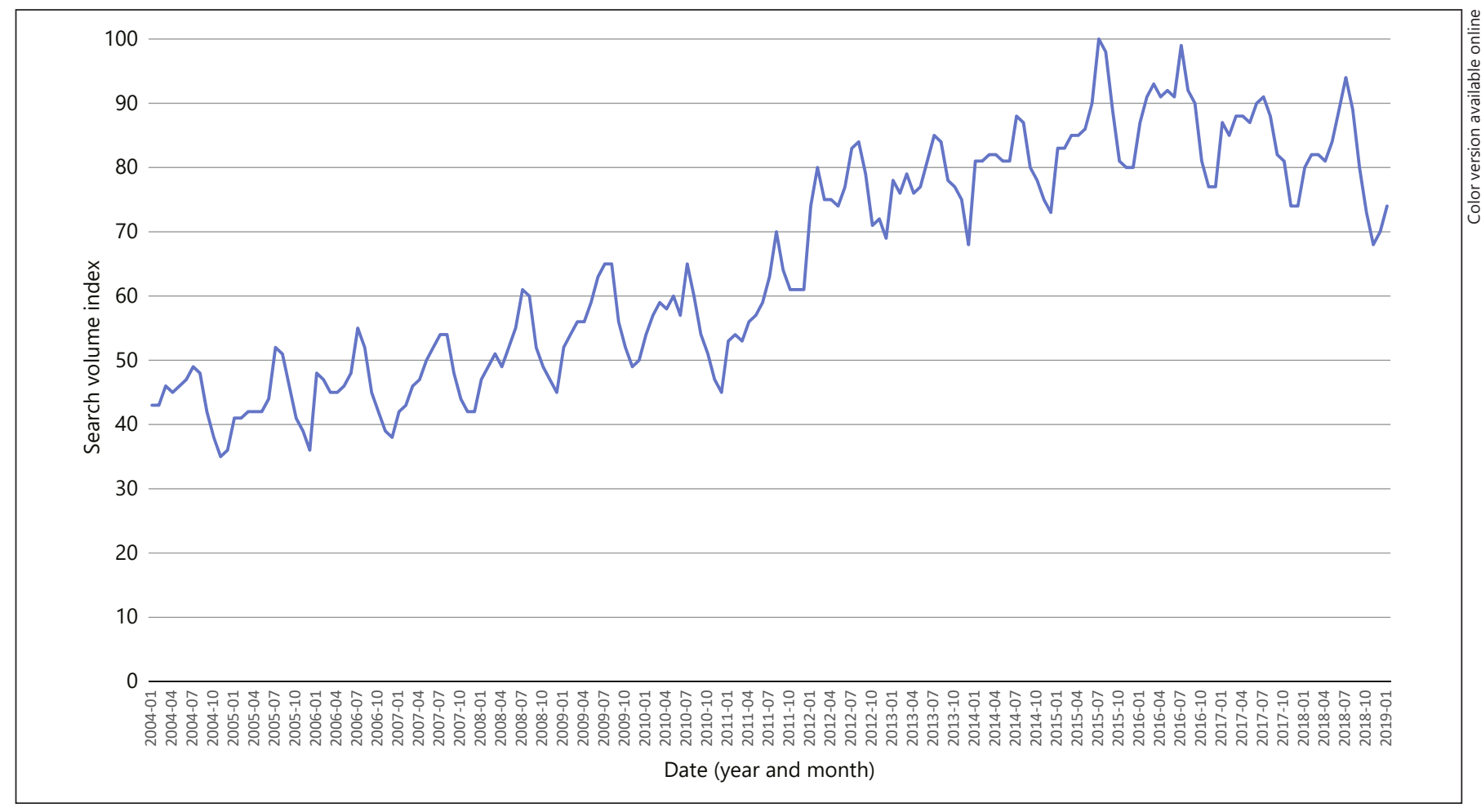

Fig. 1. Google Trends search volume indexes for “Tattoo: subject” between 2004 and 2018, worldwide.

\section{KARGER}

(c) 2019 S. Karger AG, Basel

E-Mail karger@karger.com

www.karger.com/drm
Nicolas Kluger

Department of Dermatology, Skin and Allergies Hospital

Helsinki University Central Hospital, Meilahdentie 2, PO Box 160

FI-00029 Helsinki (Finland)

E-Mail nicolas.kluger@ hus.fi 
Table 1. The top 20 countries in worldwide search volume indexes for the topic "Tattoo: subject"

\begin{tabular}{rlllll}
\hline & 2006 & 2010 & 2014 & 2018 & $2004-2018$ \\
\hline 1 & Puerto Rico (100) & Puerto Rico (100) & Argentina (100) & Costa Rica (100) & Costa Rica (100) \\
2 & Brazil (97) & Australia (91) & Porto Rico (98) & Brazil (90) & Argentina (100) \\
3 & Bulgaria (94) & USA (91) & Costa Rica (91) & Argentina (90) & Puerto Rico (98) \\
4 & Canada (92) & New Zealand (86) & Brazil (90) & Greece (85) & Uruguay (97) \\
5 & Sweden (92) & Canada (83) & Uruguay (88) & Mexico (85) & Paraguay (97) \\
6 & USA (84) & Brazil (83) & Paraguay (85) & Uruguay (83) & Brazil (95) \\
7 & Australia (81) & Norway (81) & Chili (82) & Colombia (77) & Mexico (79) \\
8 & New Zealand (78) & Sweden (81) & Panama (75) & Paraguay (75) & Colombia (79) \\
9 & Latvia (76) & Ireland (75) & Colombia (66) & Puerto Rico (70) & Panama (77) \\
10 & Portugal (73) & UK (75) & Mexico (64) & Panama (70) & USA (68) \\
11 & Argentina (73) & Philippines (75) & USA (64) & Bolivia (68) & Greece (65) \\
12 & Slovakia (68) & Bulgaria (72) & Australia (62) & Ecuador (62) & Ecuador (65) \\
13 & Greece (65) & Denmark (70) & Italy (61) & Chili (62) & Philippines (64) \\
14 & Italy (63) & Estonia (72) & Venezuela (61) & Guatemala (59) & Australia (64) \\
15 & UK (63) & Argentina (70) & UK (58) & Philippines (55) & Italy (62) \\
16 & Croatia (63) & Greece (64) & New Zealand (56) & Dominican Republic (55) & Bolivia (61) \\
17 & South Africa (57) & Costa Rica (64) & Spain (56) & Spain (55) & New Zealand (61) \\
18 & Finland (55) & Austria (62) & Philippines (56) & USA (53) & UK (61) \\
19 & Ireland (55) & Finland (62) & Austria (54) & Italy (50) & Spain (56) \\
20 & Spain (55) & Hungary (62) & Canada (57) & UK (48) & \\
\hline
\end{tabular}

2008), $65 \pm 11$ (2009-2013), and $84 \pm 7$ (2014-2018). Seasonal peaks are observed every year during summer, while searches reach their lowest during winter. In the northern hemisphere, searches peak in July-August, while in the southern hemisphere they peak around January. For the overall period 2004-2018, only Latin American countries are in the top 10 searches. They account for 12 of the top 20 countries. The Philippines are the only Asian country in the top 20. Analyses per year show that there are regional trends (Nordic European countries, East European countries) according to years, nevertheless Central and South American countries remain predominant (Table 1; data shown only for years 2006, 2010, 2014, and 2018).

\section{Discussion}

Our results reveal that there is a considerable and consistent interest in tattoos in Latin America. We cannot extrapolate from Google Trends data the relative prevalence of tattoos in Latin American countries compared to other countries. We can only comment that the prevalence of tattoos in the USA is $29 \%$, while it ranks 11 here [2]. Our findings suggest the necessity of researching the epidemiology of tattoos in Latin American countries. We failed to find large studies about tattooing in general populations in South America [4]. However, Latin American football teams enrolled in the FIFA World Cup 2018 had the highest prevalence of tattooed players $[5,6]$. This high prevalence among young players may illustrate the current trend in those countries. The seasonal variations regarding search volumes may be related to an increased interest in tattoos during summer and sunny periods. Individuals display their tattooed skin, which may trigger interest for others. Besides, news media may also favor tattoo-related articles during this period of the year, which would increase the search volume during that period. The limitations of our studies are well-known:
Google Trends is not a real epidemiological instrument and only individuals with access to the Internet can be accounted for. In Latin America, only $57 \%$ of the population uses the Internet, compared to $77 \%$ in the USA and $86 \%$ in Australia [7]. Thus, the population is not fully representative of the general population.

Acknowledging the limits of our study, it appears that there is a current and important interest in tattoos in Latin America. Further studies about tattooing and its impact on the general population is warranted on the Latin continent.

\section{Key Message}

Google Trends analysis shows an increased search volume for the topic "Tattoo" between 2004 and 2018 with summer peaks and from Latin American countries.

\section{Statement of Ethics}

The study did not require ethical approval by an institutional review board.

\section{Disclosure Statement}

The author declares no conflict of interest. There were no funding sources for this work.

\section{References}

1 Kluger N. Epidemiology of tattoos in industrialized countries. Curr Probl Dermatol. 2015;48:6-20.

2 Shannon-Missal L. Tattoo Takeover: Three in ten Americans have tattoos, and most don't stop at just one. The Harris Poll \#12 [cited 2016 Feb 10]. Available from: https://theharrispoll.com/tattoos-can-take-anynumber-of-forms-from-animals-to-quotes-to-cryptic-symbols-and-appear-in-all-sorts-of-spots-on-our-bodies-some-visible-in-everydaylife-others-not-so-much-but-one-thi/. 
3 Nuti SV, Wayda B, Ranasinghe I, Wang S, Dreyer RP, Chen SI, et al. The use of google trends in health care research: a systematic review. PLoS One. 2014 Oct;9(10):e109583.

4 Bicca JF, Duquia RP, Breunig JA, de Souza PR, Almeida HL Jr. Tattoos on 18-year-old male adolescents-characteristics and associated factors. An Bras Dermatol. 2013 Nov-Dec;88(6):925-8.
5 Kluger N, Samimi M. Tattoos among elite football players during the 2018 FIFA World Cup Russia. J Eur Acad Dermatol Venereol. 2018 Nov; https://doi.org/10.1111/jdv.15338.

6 Müller SM, Hogg S, Itin P. Tattoos and Penalty Success at the FIFA World Cup 2018. Dermatology. 2018;234(5-6):226-8.

7 The World Bank. World Development Indicators: The information society [accessed 2019 Jan 7]. http://wdi.worldbank.org/table/5.12\#. 